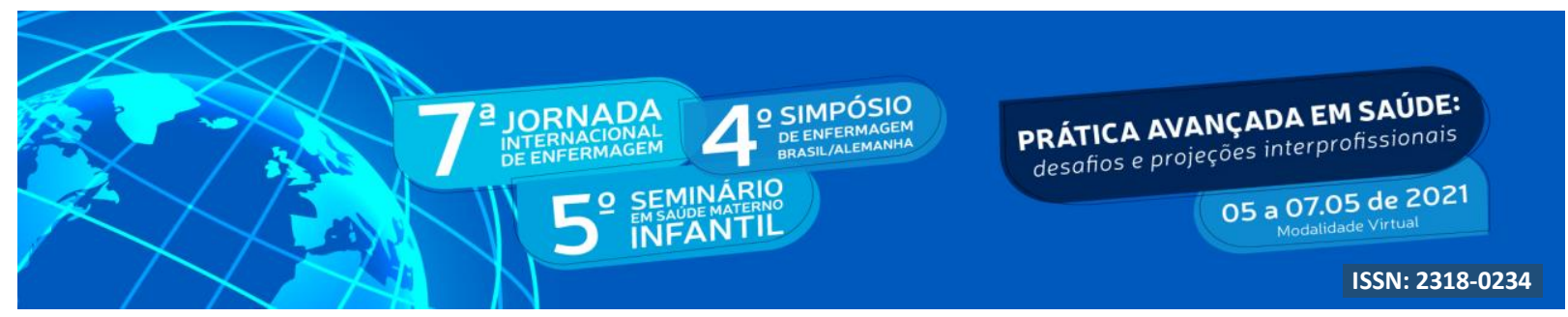

DOI: http://doi.org/10.48195/jie2021-175

\title{
LUDICIDADE PARA EVOLUIR: ATUAÇÃO E PERCEPÇÕES DE UMA VISITADORA DO PROGRAMA PRIMEIRA INFÂNCIA MELHOR ${ }^{1}$
}

\author{
Francielle Dutra da Silva²; Juliana Silveira Colomé ${ }^{3}$
}

\begin{abstract}
RESUMO
Este estudo tem como objetivo relatar a experiência de uma visitadora do programa Primeira Infância Melhor, acerca da atuação e atividades realizadas com as famílias inscritas no programa. Foram realizadas atividades com 17 famílias, constituídas por gestantes ou crianças de zero a seis anos. Cada família recebeu um atendimento singular a fim de desenvolver, principalmente, áreas como: motricidade, cognição, socioafetividade, linguagem e comunicação. O programa também visa facilitar o acesso ao serviço de saúde, dado que os visitadores estão inseridos semanalmente na rotina familiar, identificando demandas e realizando o encaminhamento ao setor responsável. O estudo mostrou a importância do programa no auxílio ao desenvolvimento na primeira infância, fortalecendo relações e favorecendo o bem-estar e segurança. Devido a isso, o Primeira Infância Melhor é um processo transformador para as famílias e para quem atua, visto que a vivência transforma o visitador em um profissional acolhedor e humano.
\end{abstract}

Palavras-chave: Colaboração intersetorial; Desenvolvimento infantil; Visita domiciliar.

\begin{abstract}
This study aims to report the experience of a visitor of the Better Early Childhood program about the performance and activities carried out with the families enrolled in the program. Activities were carried out with 17 families, consisting of pregnant women or children aged zero to six years. Each family received a unique care in order to develop, mainly, areas such as: motricity, cognition, socioaffectivity, language and communication. The program also aims to facilitate access to the health service, since the visitors are inserted weekly in the family routine, identifying demands and making the referral to the responsible sector. The study showed the importance of the program in assisting early childhood development, strengthening relationships and favoring well-being and safety. Because of this, Better Early Childhood program is a transformative process for families and for those who act, since the experience transforms the visitador into a welcoming and human professional.
\end{abstract}

Key Words: Intersectoral collaboration; Child development; Home visit.

\footnotetext{
${ }^{1}$ Relato de experiência vinculado ao Eixo Atenção integral à saúde.

${ }^{2}$ Graduanda do Curso de Odontologia. Universidade Franciscana. E-mail: fran_dutra_silva@hotmail.com

${ }^{3}$ Orientadora. Doutora em Enfermagem, docente do Curso de Enfermagem e do Mestrado em Ciência da Saúde e da Vida. Universidade Franciscana. E-mail: julian@ufn.edu.br
} 


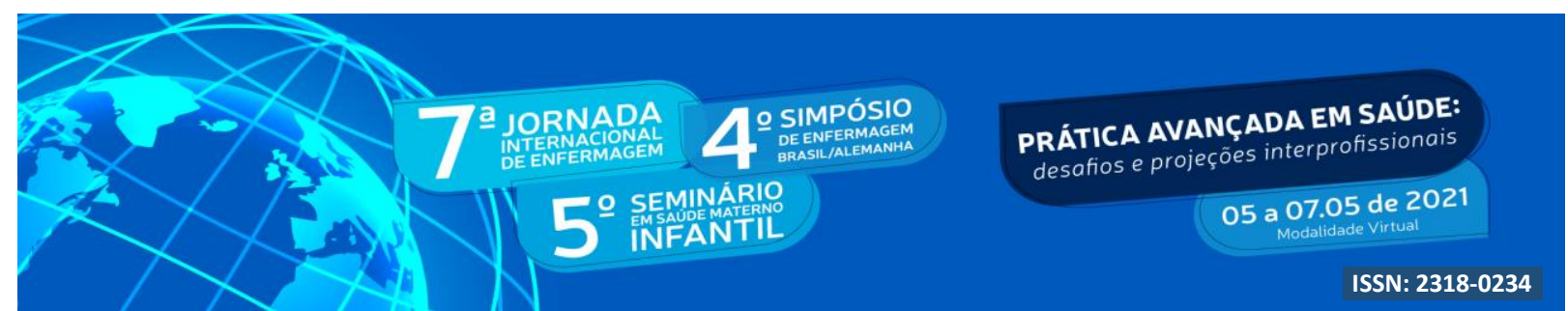

\section{INTRODUÇÃO}

A primeira infância é um período que consiste do nascimento até os seis anos de idade e equivale a um momento único na vida, dado que nesse período acontecem eventos marcantes, como os primeiros passos, as primeiras palavras e o início da formação de vínculos. Esse início de vida pode influenciar no futuro das crianças (SANTOS et al., 2019). Para o desenvolvimento integral ideal, cada criança precisa de muito afeto, amparo, atenção e dedicação familiar. Diante disso, é fundamental que a criança esteja inserida em um ambiente respeitoso, que remeta segurança, com acesso à alimentação, educação e saúde (FORLIN et al., 2019).

Entretanto, nem sempre o contexto familiar encontra-se com esses aspectos. Em alguns momentos, enfrentam outros desafios, como a violência, pobreza e falta de tempo, devido à rotina familiar (BRITO; PONTES; FROTA, 2018). O Primeira Infância Melhor (PIM), política do estado do Rio Grande do Sul, implantada em 2003, é uma ação transversal, que visa promover o desenvolvimento integral na primeira infância. Através de visitas domiciliares semanais, busca o envolvimento familiar, comunitário e intersetorial, integrando ao cuidado, os eixos da educação, saúde e assistência social (RIO GRANDE DO SUL, 2018a).

O programa atua em famílias vulneráveis e de risco e possui o intuito de fortalecer laços. Dessa maneira, contribui no desenvolvimento das crianças, com atividades lúdicas dedicadas a potencializar a cognição, motricidade, socioafetividade, comunicação e linguagem (RIO GRANDE DO SUL, 2018a). O programa tem como constituintes da equipe o Comitê de Gestores do PIM, Grupo Técnico Estadual (GTE) e Grupo Técnico Municipal (GTM), digitadores, monitores e visitadores. Os visitadores desempenham o papel de planejamento das atividades a serem realizadas e executam as mesmas, respeitando a cultura e experiências de cada família e seguindo a metodologia do programa (RIO GRANDE DO SUL, 2018b).

Atualmente, existem, na literatura, diversos estudos sobre a importância dos cuidados na infância (ALTAFIM et al., 2020). Todavia, ainda são poucos os trabalhos sobre o papel de um visitador atuando em conjunto com as famílias para o desenvolvimento de seus filhos, apesar do impacto ser reconhecido (SANTOS et al., 2019). Desse modo, esse trabalho busca mostrar como a atuação de uma visitadora do PIM pode complementar a instrução familiar para potencializar o desenvolvimento infantil. 


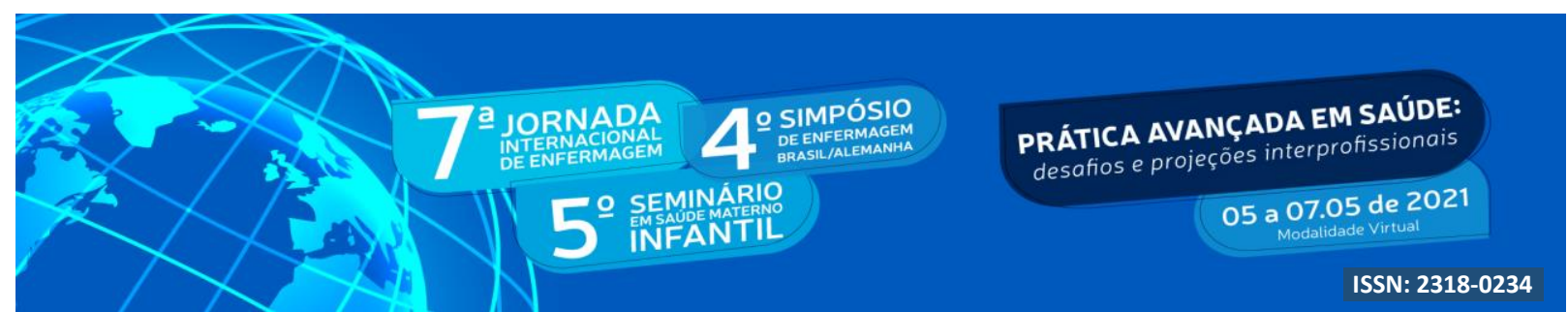

\section{OBJETIVO}

Relatar a experiência de uma visitadora do Primeira Infância Melhor acerca da atuação e atividades realizadas com as famílias inscritas no programa, em um loteamento na região Norte da cidade de Santa Maria, Rio Grande do Sul.

\section{METODOLOGIA}

O presente estudo trata-se de um relato de experiência descritivo do programa Primeira Infância Melhor, onde foram realizadas atividades com 17 famílias constituídas por gestantes ou crianças de zero a seis anos. Cada família aceitou receber o programa e, através do marco inicial do desenvolvimento, foram elaborados planos singulares de atividades.

A visitação foi realizada semanalmente, com duração de 30 minutos, no período de outubro de 2019 a fevereiro de 2021. As atividades foram elaboradas previamente com intuito de desenvolver ou ampliar alguma capacidade, juntamente com a família. Os materiais de escolha para confecção são reutilizáveis, pela facilidade do acesso, tornando possível a reprodução dos brinquedos e atividades condizentes com a realidade da família.

Cada atuação subdividiu-se em 3 momentos. O inicial teve o intuito de retomar a atividade anterior, apresentação da atividade do dia e o material utilizado e explicar qual o papel da família. Já no segundo momento desenvolveu-se a modalidade com execução das atividades pela família e criança, contando com a participação do visitador - observando ou auxiliando. Após a finalização, a criança permanecia na dinâmica ou era conduzida para atividade livre, sendo reorganizado o ambiente.

No momento final, foram observados os progressos, dificuldades e dúvidas. Desse modo, teve o intuito de retomar o objetivo, incentivando a participação familiar e executando durante a semana o que foi aprendido, orientados pelo guia da família. Nesse momento, podese reforçar o acesso à rede de serviços, educação, saúde, assistência social ou outros, se necessário.

O guia da família, fornecido aos participantes, é um livro que contém as atividades, informa o que cada criança pode fazer, de acordo com a sua faixa etária de desenvolvimento e, ainda, dicas sobre alimentação, sono e cuidados de higiene (RIO GRANDE DO SUL, 2016). 


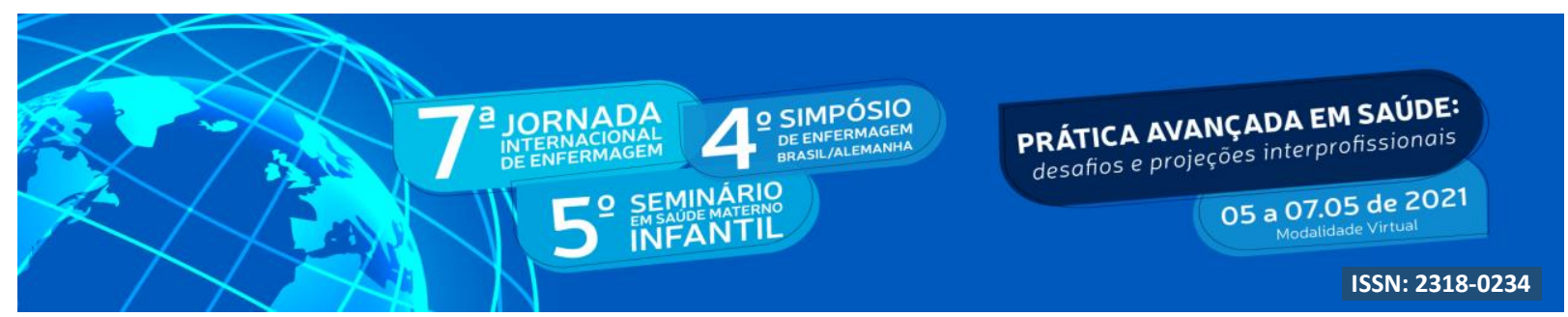

\section{DESENVOLVIMENTO}

Cada criança precisa ser motivada a aprender e desafiada a evoluir, respeitando seu próprio tempo. Quando não ocorre o incentivo, pode-se notar um atraso no seu desenvolvimento, portanto, a dedicação de tempo familiar, nessa fase, é essencial (BRASIL, 2012). Tendo como objetivo o crescimento saudável dos filhos, diversas famílias aceitaram o compromisso de participar do programa, percebendo dificuldades e estipulando metas com esforço mútuo, dispostos a garantir o resultado.

O marco inicial de desenvolvimento demonstra o marco zero, de como a criança estava naquela idade, em relação ao ideal da faixa etária, e o monitoramento trimestral, semestral ou anual registra sua evolução ou dificuldades. Para tanto, cada atividade foi planejada de acordo com as necessidades da família e da criança (RIO GRANDE DO SUL, 2016).

Para o atendimento à gestante, foi preconizado o vínculo mãe e bebê e realizada a confecção de um diário de sentimentos, visto que a mãe era menor de idade e surgiram alguns conflitos internos em relação à gestação. Nesse momento, foram passadas para a família informações sobre o pré-natal, parto e aleitamento materno. O aleitamento materno tem a capacidade de suprir a nutrição do bebê, além de proporcionar vínculo com a mãe, durante este período de troca. Em relação ao desenvolvimento, este ato promove o bom funcionamento da deglutição, respiração, sucção, entre outros benefícios (ROSA; DELGADO, 2017).

Para as crianças, o atendimento domiciliar, através do programa, oportuniza ganhos a curto prazo, como aprimorar a motricidade, cognição, socioafetividade, linguagem e comunicação (RIO GRANDE DO SUL, 2018a). A motricidade é uma das habilidades a serem exploradas, ela vai evoluindo em fluxo contínuo gradativamente em relação à idade, seguindo sequências de aprendizado e podendo ser estimulada de diversas formas (JESUS et al., 2020).

Pequenos avanços são necessários - como abrir e fechar as mãos, pegar objetos e trocar de mão, movimentos de pinça com os dedos indicador e polegar, denominada polpa-a-polpa dado que concedem habilidades de delicadeza e precisão (FERREIRA et al., 2011), são exemplos do que foi desenvolvido e cada etapa resultou na evolução de algum aspecto. Já a motricidade grossa, consiste em movimentos que desenvolvam os músculos do corpo (SIQUEIRA et al., 2019). A execução de mover os pés, atividades de engatinhar, abaixar e levantar, testes de lateralidade com bola e circuitos foram realizados com suporte, amparo e segurança. 


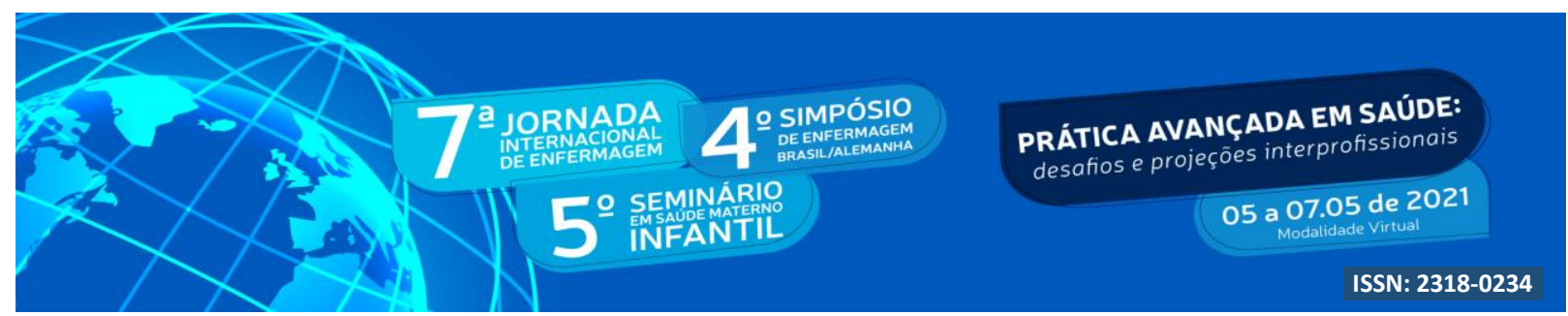

A cognição está relacionada com as capacidades mentais (TENÓRIO et al., 2019) e, na infância, sua estimulação pode ocorrer de diversas formas. Durante o período de visitas, optouse por proporcionar a elaboração de estratégias com o uso da criatividade e aperfeiçoamento da memória através de jogos lúdicos e criação de histórias. Para recém-nascidos, os estímulos do som da voz e gestos são fundamentais no processo de aprendizado e vínculo. O contato através do olhar, da expressão facial, o ato de nomear fatos do cotidiano e pessoas, foram executadas para iniciar ou complementar a comunicação.

A comunicação inicia de forma não verbal através da interação e observação, com isso a criança compreende e inicia a tentativa de imitar sinais (CAMARGO et al., 2015) até evoluir para o balbuciar e formação de palavras. Para contribuir no avanço, foram utilizadas dinâmicas com onomatopeias, reproduzindo sons conhecidos do cotidiano da criança. Para o desenvolvimento socioafetivo, apenas o curto período da visita domiciliar não seria suficiente. Conforme Bowlby (1969/2002), o apego é construído através de uma relação que proporcione segurança. Esses laços demandam tempo, confiança e dedicação. A iniciativa de ter um período do dia exclusivo para atender a criança, com a metodologia do programa, facilita no processo, mas a dedicação no dia a dia resulta no estreitamento e união da família.

As atividades sobre indicar as qualidades dos familiares e desenhar o que a criança mais gosta de fazer com a família, foram didáticas utilizadas para mostrar a importância da família para a criança, e como existe reconhecimento dentro do âmbito familiar. Outros aspectos foram valorizados, como a autonomia, que favorece o processo de aprendizado, desde pequenas escolhas (PORTUGAL; GABRIEL; PICCININI, 2019), como engatinhar, segurar os talheres ou o copo, iniciando a formação de preferências, até evoluir para a realização de atividades domésticas.

Ademais, a alimentação saudável e hábitos de higiene configuram temas relevantes na abordagem com as famílias. Através de brinquedos demonstrativos, buscou-se orientar bons exemplos entre os membros do contexto familiar, servindo como espelho para a criança. A infância é um período em que novos hábitos estão se consolidando, tornando propícia a promoção de reflexão sobre os alimentos (DONADONI; COSTA; NETTO, 2019). Nesse período, faz-se importante adequar a realidade da família, dado que o comportamento alimentar está sendo estruturado.

O programa visa facilitar o acesso ao serviço de saúde, visto que os visitadores estão inseridos semanalmente na rotina familiar, identificando demandas e realizando o 


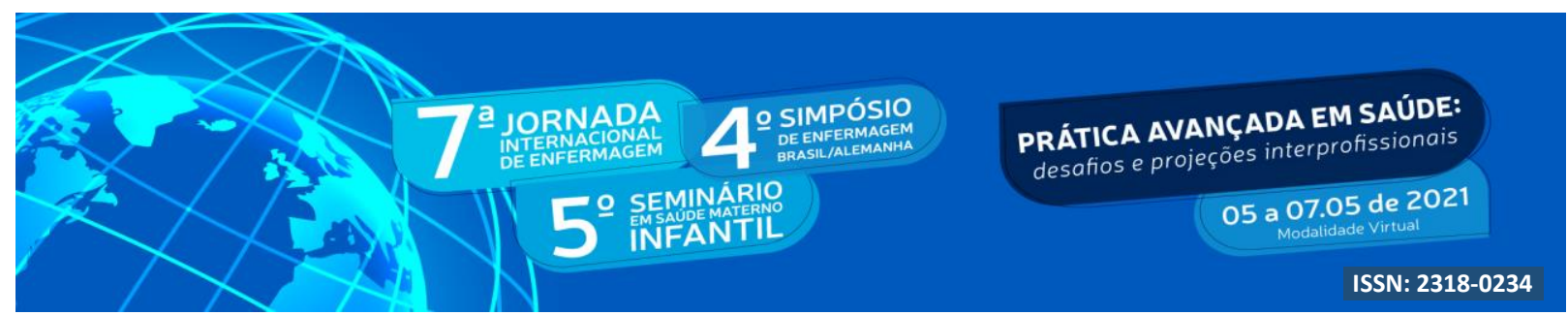

encaminhamento ao setor responsável. A área da saúde tem papel fundamental no cuidado às gestantes, visando reduzir a mortalidade infantil e orientar sobre o parto e dúvidas subsequentes. Para crianças, o controle da vacinação, consultas e informações são possíveis através do programa (RIO GRANDE DO SUL, 2018a).

$\mathrm{Na}$ área da Educação, o acesso ao serviço pode identificar evasão escolar, dessa forma, busca-se orientar o retorno, incentivando a permanência e o foco nos estudos. A assistência social torna possível o acesso a outros programas de distribuição de renda, diminuindo a desigualdade social e sendo suporte em casos de violência ou negligência (RIO GRANDE DO SUL, 2018a).

A primeira infância demonstrou ser um período farto de aprendizados, atrelado aos cuidados e identificações de demandas, para favorecer o crescimento e desenvolvimento saudável. Afinal, o slogan do programa, "O que você faz pelo seu filho hoje, vale para toda a vida", indica sua importância, contribuindo para uma infância melhor (RIO GRANDE DO SUL, 2018a).

\section{CONCLUSÃO}

O estudo mostrou a importância do programa PIM no auxílio ao desenvolvimento na primeira infância, fortalecendo relações entre os membros da família, identificando demandas e favorecendo o bem-estar e segurança. Dessa forma, permitindo contemplar a rotina de um visitador domiciliar e o seu papel na realização das atividades e orientações.

Para as famílias, foi possível criar ou ampliar vínculos, sendo notável o desejo e comprometimento em desenvolver seus filhos. Para as crianças, receber apoio, brincar e ter dedicação exclusiva na infância é fundamental, repercutindo em diversos aspectos da vida. A vivência como visitador do programa proporciona um contato semanal, formando maior vínculo com as famílias, mas requer conhecimento. Ao atender diversas realidades e pessoas diferentes, o visitador deve estar liberto de julgamentos e se faz necessário conhecer o contexto em que vai estar inserido. É um processo transformador para quem atua, formando um profissional mais acolhedor, humano e acessível.

\section{REFERÊNCIAS}




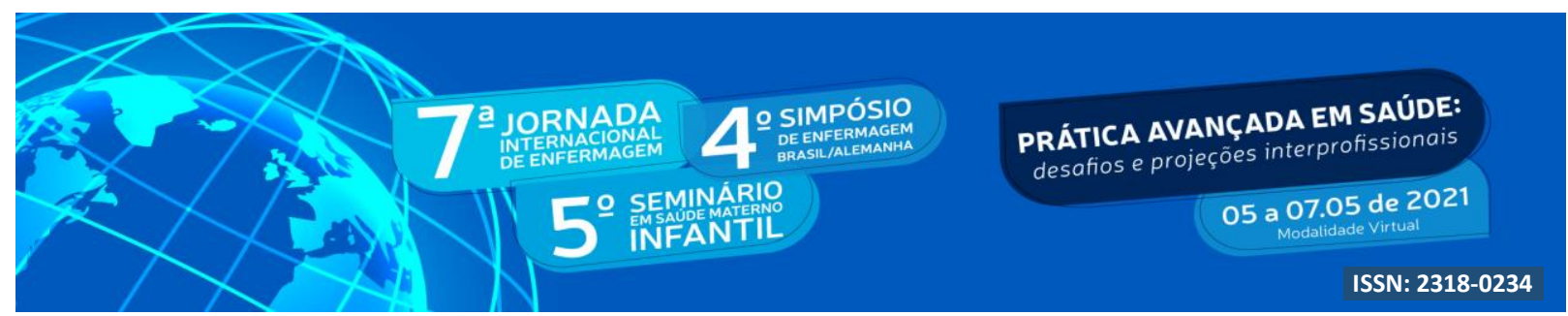

ALTAFIM, E. R. P. et al. Measuring early childhood development in Brazil: validation of the Caregiver Reported Early Development Instruments (CREDI). Jornal de Pediatria, Porto Alegre, v. 96, n. 1, p. 66-75, jan./fev. 2020.

BOWLBY, J. Apego: a natureza do vínculo. São Paulo: Martins Fontes, 2002. v.2: apego e perda. (Obra original publicada em 1969)

BRASIL. Ministério da Saúde. Secretaria de Atenção à Saúde. Departamento de Atenção Básica. Saúde da criança: crescimento e desenvolvimento. Brasília: MS, 2012. (Cadernos de Atenção Básica, nº 33).

BRITO, R.; PONTES, H.; FROTA, M. Um retrato da primeira infância em situação de pobreza. Revista Brasileira em Promoção da Saúde, Fortaleza, v. 31, n. 4, p. 1-8, out./dez. 2018.

CAMARGO, J. F. et al. Os gestos na comunicação mãe e bebê: um estudo longitudinal. Estudos e Pesquisas em Psicologia, Rio de Janeiro, v. 15, n. 2, p. 652-670, jul. 2015.

DONADONI, P.; COSTA, J. A. S.; NETTO, M. P. Nutrindo o saber: relato de experiência em práticas de educação alimentar e nutricional com pré-escolares. Revista de APS, Juiz de Fora, v. 22, n. 1, p. 203-214, jan./mar. 2019.

FERREIRA, A. C. C. et al. Força de preensão palmar e pinças em indivíduos sadios entre 6 e 19 anos. Acta Ortopédica Brasileira, São Paulo, v. 19, n. 2, p. 92-97, 2011.

FORLIN, K. A. et al. Marcas da maternidade: do ventre para a vida toda. Revista Brasileira de Psicodrama, São Paulo, v. 27, n. 2, p. 186-198, jul./dez. 2019.

JESUS, D. R. F. et al. Associação entre a qualidade de vida, qualidade do sono e desenvolvimento motor de crianças. Arquivos de Ciências da Saúde da UNIPAR, Umuarama, v. 24, n. 2, p. 95-99, maio/ago. 2020.

PORTUGAL, P. N.; GABRIEL, M. R.; PICCININI, C. A. Espaço do berçário: contribuições de um programa de acompanhamento. Arquivos Brasileiros de Psicologia, Rio de Janeiro, v. 71, n. 1, p. 36-53, jan./abr. 2019.

RIO GRANDE DO SUL. Secretaria Estadual da Saúde. Departamento de Ações em Saúde. O PIM: o que é. 2018a. Disponível em: http://www.pim.saude.rs.gov.br/site/o-pim/o-que-e/.

Acesso em: 07 mar. 2021.

RIO GRANDE DO SUL. Secretaria Estadual da Saúde. Departamento de Ações em Saúde. O PIM: quem participa. 2018b. Disponível em: http://www.pim.saude.rs.gov.br/site/opim/quem-participa. Acesso em: 08 mar. 2021.

RIO GRANDE DO SUL. Secretaria Estadual da Saúde. Programa Primeira Infância Melhor. Guia da Família. 7. ed. Porto Alegre: Companhia Rio Grandense de Artes Gráficas (CORAG), 2016. 


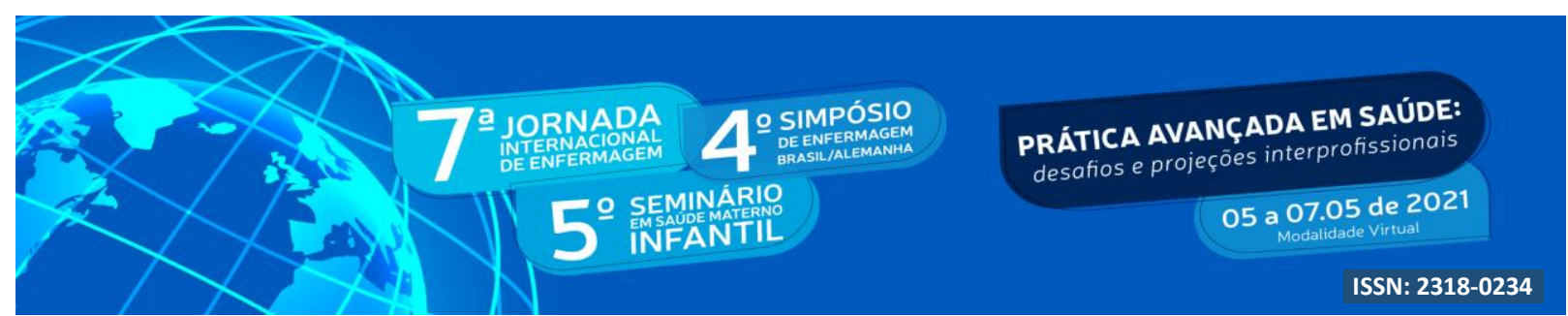

ROSA, J. B. S.; DELGADO, S. E. Conhecimento de puérperas sobre amamentação e introdução alimentar. Revista Brasileira em Promoção da Saúde, Fortaleza, v. 30, n. 4, p. 19, out./dez. 2017.

SANTOS, G. S. et al. Contribuições da Primeira Infância Melhor para o crescimento e desenvolvimento infantil na percepção das famílias. Revista de Pesquisa: Cuidado é Fundamental Online, Rio de Janeiro, v. 11, n. 1, p. 67-73, jan./mar. 2019.

SIQUEIRA, K. C. F. et al. Rotina pré-escolar e desenvolvimento infantil de crianças atendidas em uma escola pública no interior de São Paulo. Revista Brasileira de Ciência \& Movimento, Brasília, v. 27, n. 4, p. 5-12, 2019.

TENÓRIO, L. G. M. et al. Comparação de habilidades cognitivas de crianças a termo e prétermo. Distúrbios da Comunicação, São Paulo, v. 31, n. 1, p. 44-53, mar. 2019. 